\title{
A numerical study on the robustness and efficiency of the PL homotopy algorithm for solving unconstrained optimization problems
}

\author{
ANDREI BOZANTAN ${ }^{1}$ and VASILE BERINDE ${ }^{1,2}$
}

\section{ABSTRACT.}

Our aim in this paper is to illustrate the relevance of the fixed point piecewise-linear homotopy algorithm for solving unconstrained optimization problems. The numerical tests are performed by using an implementation of the piecewise-linear homotopy algorithm in the modern programming language C\#, as described previously in [Bozantan, A., An implementation of the piecewise-linear homotopy algorithm for the computation of fixed points, Creat. Math. Inform., 19 (2010), No. 2, 140-148] and [Bozantan, A. and Berinde, V., Applications of the PL homotopy algorithm for the computation of fixed points to unconstrained optimization problems, Creat. Math. Inform., 22 (2013), No. 1, 41-46]. As shown by the numerical experiments done on a set of classic test functions in optimization theory, the PL homotopy algorithm appears to be more reliable than the classical Newton's method and some other important methods for finding local or global minima.

Acknowledgement. This work was partially financed by European Social Fund through the Sectoral Operational Programme Human Resources Development 2007-2013. The second author's research was supported by the Grants PN-II-RU-TE-2011-3-239 and PN-II-ID-PCE-2011-3-0087 of the Romanian Ministry of Education and Research.

\section{REFERENCES}

[1] Allgower, E. L. and Georg, K., Introduction to numerical continuation methods, Springer-Verlag, Berlin, 1990

[2] Berinde, V., Iterative Approximation of Fixed Points, Springer, Berlin Heidelberg New York, 2007

[3] Bongartz, I., Conn, A. R., Gould, N. I. M. and Toint, P. L., CUTE: Constrained and unconstrained testing environments, ACM Trans. Math. Software, 21 (1995), 123-160

[4] Bozantan, A., An implementation of the piecewise-linear homotopy algorithm for the computation of fixed points, Creat. Math. Inform., 19 (2010), No. 2, 140-148

[5] Bozantan, A., New implementations of fixed point iterative algorithms and applications to nonsmooth optimization, PhD Thesis, North University Center at Baia Mare, Technical University of Cluj-Napoca, 2014

[6] Bozantan, A. and Berinde, V., Applications of the PL homotopy algorithm for the computation of fixed points to unconstrained optimization problems, Creat. Math. Inform., 22 (2013), No. 1, 41-46

[7] Bozantan, A. and Berinde, V., About the implementation and some applications of the FIXPOINT software minipackage, Creat. Math. Inform., 23 (2014), No. 1, 41-50

[8] Cegielski, A., Iterative Methods for Fixed Point Problems in Hilbert Spaces, Lecture Notes in Mathematics, 2057, Springer-Verlag, Berlin, 2013

[9] Chidume C.E. and Măruşter, Şt., Iterative methods for the computation of fixed points of demicontractive mappings, J. Comput. Appl. Math., 234 (2010), 881-882

[10] Eaves, C. B., Homotopies for computation of fixed points, Mathematical Programming, 3 (1972), No. 1, 1-22

[11] Eaves, C. B. and Saigal, R., Homotopies for computation of fixed points on unbounded regions, Mathematical Programming, 3 (1972), No. 1, 225-237

[12] Edgar, T. F., Himmelblau, D. M., Lasdon, L. S., Optimization of Chemical Processes, Second Edition, McGraw-Hill, 2001

[13] Floudas, C. A., Pardalos, P. M., Adjiman, C. S., Esposito, W. R., Gumus, Z. H., Harding, S. T., Klepeis, J. L., Meyer, C. A. and Scheiger, C. A., Handbook of Test Problems in Local and Global Optimization, Springer, 1999

[14] Hedar, A., Test function web pages, http://www-optima.amp.i.kyoto-u.ac.jp/member/student/hedar/ Hedar files/TestGO files/Page364.htm

[15] Herings, P. J.-J. and Peeters, R., Homotopy methods to compute equilibria in game theory, Economic Theory, 42 (2010), No. 1, 119-156

[16] Güler, O., Foundations of Optimization, Graduate Texts in Mathematics, 258, Springer, 2010

[17] Istratescu, V. I., Fixed Point Theory. An Introduction, Kluwer Academic Publishers, 2001

[18] Kelley, C. T., Iterative Methods for Optimization, SIAM, Philadelphia, 1999

[19] Kuhn, H. W., Simplicial approximation of fixed points, Proceedings of the National Academy of Sciences of the United States of America, 61 (1968), No. 4, 1238

[20] Lemke, C. E., Bimatrix equilibrium points and mathematical programming, Management science, 11 (1965), No. 7, 681-689

[21] Merrill, O. H., Applications and extensions of an algorithm that computes fixed points of certain upper semi-continuous point to set mappings, Ph.D. thesis, University of Michigan., Ann Arbor, Michigan, 48106, USA (1972)

[22] Molga, M. and Smutnicki, C., Test functions for optimization needs, http://www.zsd.ict.pwr.wroc.pl/ files/docs/functions.pdf

[23] Moré, J. J., Garbow, B. S. and Hillstrom, K. E., Testing unconstrained optimization software, ACM Trans. Math. Software, 7 (1981), No. 1, 17-41

[24] Pohlheim, H., Examples of objective functions, http://www . geatbx.com(2006)

[25] Scarf, H., The approximation of fixed points of a continuous mapping, SIAM Journal on Applied Mathematics, 15 (1967), No. 5, 1328-1343

[26] Scarf, H. and Hansen, T., The computation of economic equilibria, Yale University Press New Haven, Conneticut (1973)

[27] Thele, R. L., Iterative techniques for approximation of fixed points of certain nonlinear mappings in Banach spaces, Pacific J. Math., 53 (1974), 259-266

[28] Zhang, H. C. and Hager, W. W., A non monotone line search technique and its application to unconstrained optimization, SIAM J. Optim., 14 (2004), No. 4, 1043-1056

1 Department of Mathematics and Computer Science

North University Center at Baia Mare, Technical University of Cluj-Napoca

Victoriei 76, 430122 BAIA MARE, ROMANIA

E-mail address: andrei.bozantan@gmail.com, vberinde@ubm.ro, vasile_berinde@yahoo.com 
Andrei Bozantan and Vasile Berinde

2 Department of Mathematics and Statistics

King Fahd University of Petroleum and Minerals

DHAHRAN, KINGDOM OF SAUdi ARABIA

E-mail address: vasile.berinde@gmail.com 